\title{
A test for studying sociability of the common shrew, Sorex araneus
}

\author{
Nikolay A. Shchipanov* \& Tatiana B. Demidova
}

\begin{abstract}
The common shrew Sorex araneus is one of the least social mammals with chiefly aggressive interactions. Although this species is usually considered territorial, the behavioral mechanisms of the social system are not entirely clear. Sociability is the motivation to engage in social contact, the conflict in the case of the common shrew, in the presence of both situational and individual differences, can be an important factor in the use of space in this species. This aspect of behavior of shrews was not studied. We propose a simplified preference test which could be used in field studies. In contrast to the classic Crawley three chamber test we performed trials in one-chamber arena. The test implies assay of preference of an area adjoined to wire-net container with a stimulus animal versus an area-adjoined empty container. The distance, the velocity, and the duration were considered the principal variables. Indexes permitting assay the mobility in a zone and preference of an area is suggested. This publication is devoted to the description of the test and discussing of the preliminary results.
\end{abstract}

How to cite this article: Shchipanov N.A., Demidova T.B. 2020. A test for studying sociability of the common shrew, Sorex araneus // Russian J. Theriol. Vol.19. No.2. P.105-111. doi: 10.15298/rusjtheriol.19.2.01.

KEY WORDS: sociability, preference test, Sorex araneus.

Nikolay A. Shchipanov [shchipa@mail.ru], Tatiana B. Demidova [demidovatanya@mail.ru], A.N. Severtsov Institute of Ecology and Evolution, Russian Academy of Sciences, Leninsky pr. 33, Moscow 119071, Russia.

\section{Тест для оценки коммуникабельности обыкновенной бурозубки, Sorex araneus}

\begin{abstract}
Н.А. Щипанов*, Т.Б. Демидова
РЕЗЮМЕ. Обыкновенная бурозубка Sorex araneus — одно из наименее социальных млекопитающих с преимущественно агрессивными взаимодействиями. Хотя этот вид обычно считается территориальным, поведенческие механизмы социальной системы не совсем ясны. Общительность - мотивация к участию в социальных контактах, конфликтах в случае с обыкновенной бурозубкой, при наличии как ситуативных, так и индивидуальных различий, может являться важным фактором использования пространства у этого вида. Этот аспект поведения землеройки до сих пор не был изучен. Мы предлагаем упрощенный тест определения “территориального предпочтения”, который можно использовать в полевых исследованиях. В отличие от классического трехкамерного теста Crawley, мы проводили испытания в однокамерной арене. Тест подразумевает оценку предпочтения определенной области (зоны) арены, прилегающей к сетчатому контейнеру со стимулирующим животным по сравнению с областью арены, прилегающей к пустому контейнеру. Расстояние, скорость и продолжительность присутствия животного в тои или иной области рассматривали как основные переменные. Предложены индексы, позволяющие оценить мобильность в пределах зон и предпочтение зоны.
\end{abstract}

КЛЮЧЕВЫЕ СЛОВА: коммуникабельность, тест выбора, Sorex araneus.

\section{Introduction}

Sorex shrews are considered to be solitary animals with territoriality supported by aggressive interactions (Rychlik, 1998). However, only the areas of adult mature females are isolated, whereas home ranges of males overlap ranges of both males and females and young shrews. Young shrews widely overlap areas of mature females

* Corresponding author and share peripheries of their home ranges (Shillito, 1963a, b; Churchfield, 1990; Shchipanov et al., 2005, 2019). Social interactions in various contact tests were chiefly offensive (Crowcroft, 1955, 1957; Moraleva, 1989; Churchfield, 1990; Rychlik, 1998; Shchipanov et al., 1998, 2005; Kalinin et al., 1998; Rychlik \& Zwolak, 2005, 2006; von Merten et al., 2017). However, the defense of an area was not found in large enclosures; the common shrews defended only the adjacent space, in the place where they were at the moment (Oleinichenko, 
2007,2012 ). Studying of social interactions of the shrews was performed in contact tests. Because the behavior of an animal in the contact tests influences that of the other, one can score the parameters for the pair as for a unit (File \& Hyde, 1978; File \& Seth, 2003). It is difficult to disentangle factors, such as social motivation, emotional stress, and motor drive (Millan \& Bales, 2013). So, although we have a general idea about the type of interactions, we do not know if there are some individual or situational differences in motivation to engage in social interaction, i.e., in sociability of animals.

Sociability is usually studied in various preference tests, i.e., measuring activity in zones of social versus non-social objects (Millan \& Bales, 2013). The classic test is conducted in a three-chamber arena with an assessment of the duration of presence in the chamber (Crawley, 2000, 2004). We used a single chamber test and measured activity in different functional zones. Such design greatly simplifies the required equipment and facilitates the recording of trials, as well as reduces a trial time, thus permit to test animals in the field studies. The idea of this study is to understand whether this simplified design allows us to obtain the data sufficient to assay sociability of the common shrew. The challenge for the study is to discriminate between the low sociability and suitability of the test. Indeed, in case of the low sociability, which is expected for these animals, it may be found not any prominent response to social stimuli. It was found that in shrews maintained in captivity in groups, the number of social interactions and the proportion of aggressions in the contact tests were significantly higher (Kalinin \& Shchipanov, 2003). Therefore, we include in this study experiments with shrews housed in pairs. The animals were maintained in field vivarium. This set the limit to the number of shrews participated in trials, as red-toothed shrews are rather complicated for captive maintenance (Churchfield \& Searle, 2008). This publication focuses on the suitability of the test and not on the study of sociability in the common shrew as such.

\section{Material and methods}

\section{Animals and housing}

Six subadult shrews were taken from the wild in August. Common shrews are usually immature in their first year of life, and both males and females have no clear gender signs. Only females of the young shrews could be distinguished by dark spots which mark the places of nipples (Croin Michelson, 1966; Searle, 1985; Churchfield \& Searle, 2008). In this study, females were identified by the dark spots on the belly, and individuals without visible female signs were attributed to males.

Shrews were housed just after the capture in individual boxes of transparent plastic with the bottom of $50 \times$ $70 \mathrm{~cm}$, equipped with a transparent shelter, $25 \times 50 \mathrm{~cm}$. The shelter beneath a lid was divided into three equal corridors. Saw chips mixed with saw dust were used as a substrate. Chicken hearts, mealworms, fly larvae, and frozen grasshoppers were used for food. Food and water were given ad libitum. Shrews were kept in open air under natural ambient temperatures and light regimen. Initially, the animals were housed in individual boxes. They were used in trials five days after removal. After first series of trials, four of those shrews were housed in pairs. Food and water were given ad libitum in each of the boxes. Animals were weighed to monitor their welfare. Under individual housing, the animals slightly rose the body mass. Housing in pairs did not significantly (ANOVA for repeated measurements) affect body mass of individuals.

\section{Ethical note}

The number of individuals used in this study was minimized, and the animals were cared for in accordance with guidelines for the treatment of animals in behavioral research and teaching (Buchanan et al., 2012). All the individuals were released at the places of capture after the study. The time of absence in the wild permitted the common shrews to reoccupy their former home ranges (Kouptsov, 2013).

\section{Design of arena}

Behavior of the animals was tested on a square arena $(50 \times 50 \mathrm{~cm})$ with two wire-mesh cylindrical containers of $12 \mathrm{~cm}$ in height and $8 \mathrm{~cm}$ in diameter. Walls of a container permitted auditory, visual, and olfactory contacts. Lids of the containers were made of white opaque plastic and not permitting contacts. The containers were posted in opposite corners, in fixed positions (Fig. 1A). Orientation of the arena relative to the cardinal points was changed at random in each of the trials. The area within $3 \mathrm{~cm}$ distance from a border of an empty container was named "free zone" - FZ, and that adjoined a container with a shrew was called "animal's zone" - AZ (Fig. 1B). When both containers were empty, the zones were marked as "north" and "south". These labels indicate position of a container at the image, but not actual spatial orientation. The border zone - BZ, is a 3-cmwide band along the walls.

\section{Trials}

The trials were performed from 6:00 to 7:00 AM, in the period of maximum activity of shrews. A total of 44 tests with 6 individuals were conducted. Each shrew was used in trials as a focal animal and as a stimulus. Shrews numbered 1 and 4 participated in four, and 2, 3, 5 , and 6 participated in eight trials as focal animals. The trials were performed in a special room with artificial lighting, roughly corresponding to the brightness of the natural light in the open air at this time (it was inferred based on similar brightness of images captured inside and outside the room). The arena was washed with water, cleaned with alcohol, and ventilated before each trial. Trials were captured by video camera (Sony Handicam) in MPEG-2 format. A stimulating animal was placed in the container right before the trial and returned back in his box just after the trial. A focal animal was released 

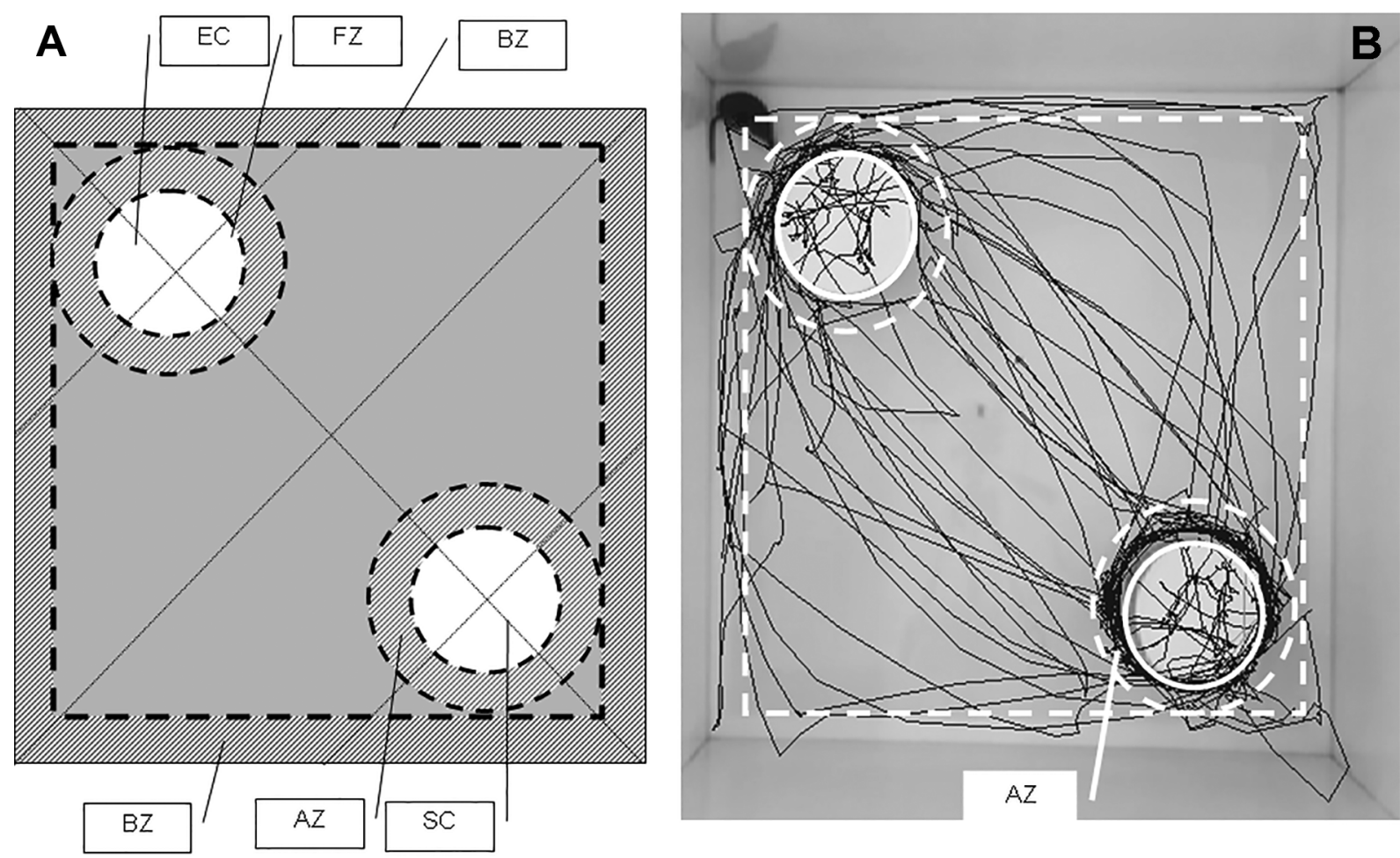

Fig. 1. Design of arena - A, and typical track of animal in a trial - B. Hatched fragments - the area of the zones: FZ - zone around empty container, AZ — zone around container with stimulus animal, BZ — border zone. White circles — the area of lids. Dotted lines indicate fixed position of the containers. Track was obtained from shrew ID3 in trial of "unfamiliar" series with shrew ID5 as stimulus animal.

manually from the plastic container in the center of the arena; then, an operator was leaving the room.

The study included three trial series. In the first series, denoted as the "control", both containers were empty. In the second and third series of trials one of the containers was with a stimulating animal. The second series, called the "experiment", was performed with animals housed individually. The third series, called "familiar", was conducted with animals of the same pair. In the fourth series, labeled "unfamiliar", tests were carried out with shrews from different pairs. Trials of each of the series were performed twice. The tests of the "control" series were interspersed with the "experimental" ones, and the "unfamiliar" ones - with the "familiar".

The distance traveled, the duration of presence, and the mean velocity in a zone were obtained from digitizing of a 6-minute videos. The records were analyzed in the program package EthoVision XT. Digitization started when operator left the room. The net digitized trial time made 300 seconds.

\section{Analyses}

Correlations between natural values of variables were studied by calculation of Spearman correlation coefficient $(R)$. Bonferroni correction was applied for multiple comparisons. Correlation of activity with body mass was estimated by plotting the mass of in- dividuals against distances traveled in trials in the day of weighting.

Shapiro-Wilk test was applied to estimate normality of datasets. Z-conversion was performed for distance and velocity variables. The arcsin transformation was applied to durations. ANOVA was performed with normalized variables in the General Linear Models module of Statistica 7.0. Residuals were found normal in all of the ANOVAs. The effect of the individuality of a focal animal and the type of trial was studied in two-way ANOVA with both ID and trial type as random factors. Post hoc comparisons were performed in Tukey HSD test.

Response to social stimulus was assessed with indexes. The motion index, $D$, estimates the density of the network of tracks in a zone in question:

$$
D_{z}=d_{z} S_{a} / d_{T} S_{z}
$$

where: $d_{z}$ is a distance traveled in a given zone $z, d_{T}$ total travelled distance, $S_{a}$ - total area of arena $2500 \mathrm{~cm}^{2}$, and $S_{z}$ - area of a given zone $z$ : for BZ, the area comprised $600 \mathrm{~cm}^{2}$, and for AZ, FZ, and North and South zones, it was approximately $104 \mathrm{~cm}^{2}$. When the distance covered in a zone in question corresponds to random movements, the index equals 1 .

The dominance index, $I_{x}$, assesses the proportion of a variable in question in $\mathrm{AZ}$ to $\mathrm{FZ}$ : 


$$
I_{x}=A Z_{x} /\left(A Z_{x}+F Z_{x}\right)-0.5
$$

where: $A Z_{x}$ and $F Z_{x}$ are the values of the considered variable $(x)$ in AZ and FZ and 0.5 is the fraction expected in the absence of reaction. The index is zero when the variables are equal. The indexes were studied in Kruskal-Wallis ANOVA.

We calculated the repeatability $r$, which is the proportion of variance across individuals (animal ID) divided by the total variance. Adjusted repeatabilities were calculated following Nakagawa \& Schielzeth (2010) using the function rpt from the R-package rptR (Stoffel et al., 2017). In each calculation, a behavioral measure was used as the response variable and animal ID as random factor and experiment number as fixed factor. The number of bootstrap iterations was set at 1000 for the $95 \%$ CI. Statistical significance of the repeatability was tested using the likelihood ratio test (LRT) implemented in rptR.

\section{Results}

The maximal total distance traveled in the trials comprised $46.6 \mathrm{~m}$. The maximal velocity, when animals swept across the arena from corner to corner, made $314 \mathrm{~cm} / \mathrm{s}$. Maximal distance covered in AZ and FZ was $884 \mathrm{~cm}$ and $1340 \mathrm{~cm}$. All the variables except of duration in BZ correlated with total traveled distance (Tab. 1). The total distance covered in a trial was in negative correlation with body mass $\left(R_{s}=-0.45 ; p<0.05\right.$ with Bonferroni correction).

The effects of ID and trial type (both as random factors) were studied in a two-way ANOVA. In both models, the effect of animal ID was significant $(p<0.003)$. Animals 2 and 6 were significantly slower overall, as a result, they covered a shorter distance $(p<0.0001)$, but were faster at AZ $(p<0.0001)$ compared to other shrews. The type of trial significantly affected only the distance traveled at free area of arena $(p<0.01$ with Bonferroni correction), the velocity $(p<0.03)$ and the time spent in AZ $(p<0.001)$. The velocity in the experimental series was significantly $(p<0.02)$ greater than that in the "control" series. Sex of both the focal and stimulus animals did not affect variables $(p>0.54)$.

The distance traveled in free area of arena was significantly $(p<0.001)$ smaller in trials with animals living in pairs compared to trials with animals housed individually, and it was not different in animals of the same regimen of housing. Traveling along the border of arena was larger when shrews lived in individual boxes, and tended to be smaller $(p<0.09)$ when animals were kept in pairs. Median of $D_{B Z}$ was 1.8 in the "control", significantly greater than $1(p<0.05)$, was not different from 1 in other trials (Fig. 2). Travels in FZ were more intensive than in BZ in all sorts of the trials. $D_{F Z}$ was on average 1.5 times greater compared to $D_{B Z}$ and significantly $(p<0.01)$ exceeded 1 . $D_{A Z}$ was 3.5 times greater compared to $D_{F Z}(p<0.05)$ in animals lived in pair, while no difference was found in shrews lived individually.
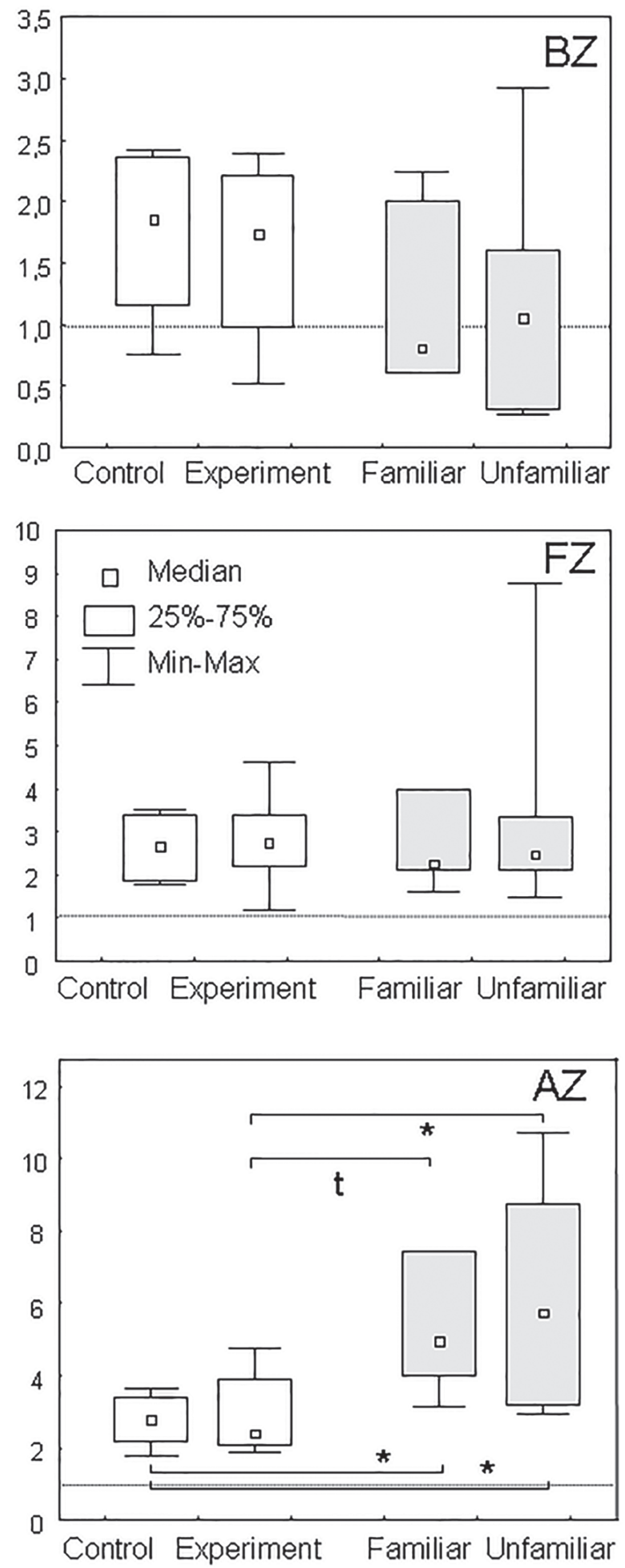

Fig. 2. Motion indexes $\left(D_{z}\right)$, in the border zone - BZ; in free zone - FZ, and in the zone of stimulus animal - AZ. The dashed line indicates an index level similar to that expected for random travel. $\mathrm{t}-p<0.07, *-p<0.05$, trials with animals from living in pairs - gray boxes. 
The index of dominance in distance, $I_{d}$, duration, $I$, and velocity, $I_{v}$, revealed differences associated with the housing regimen. Animals from pair stayed in AZ significantly longer, covered larger distance, and moved significantly slower. The indexes were significantly different from zero $(p<0.003)$ in the trials with animals living in pair (Fig. 3).

Repeatability was found in variables of velocity, distance, and in indexes of motion in BZ, FZ and AZ (Tab. 2). Duration was not normally distributed. Indexes of preference in distance and velocity were not repeatable.

Table 1. Spearman's coefficient of correlation $\left(R_{s}\right)$ of variables with the total distances covered in a trial. FZ* in the "control" trials mean both North and South zone. Significant coefficients ( $p<0.05$ with Bonferroni correction) are shown in bold.

\begin{tabular}{|c|c|c|}
\hline Variable & Zone & $R_{s}$ \\
\hline \multirow{3}{*}{ Velocity, cm/s } & $\mathrm{BZ}$ & $\mathbf{0 . 8 8}$ \\
\cline { 2 - 3 } & $\mathrm{FZ}$ & $\mathbf{0 . 3 6}$ \\
\cline { 2 - 3 } & $\mathrm{AZ}$ & $\mathbf{0 . 8 5}$ \\
\hline \multirow{3}{*}{ Distance, cm } & $\mathrm{BZ}$ & $\mathbf{0 . 7 7}$ \\
\cline { 2 - 3 } & $\mathrm{FZ}$ & $\mathbf{0 . 8 7}$ \\
\cline { 2 - 3 } & $\mathrm{AZ}$ & $\mathbf{0 . 8 7}$ \\
\hline \multirow{3}{*}{ Duration, s } & $\mathrm{BZ}$ & -0.18 \\
\cline { 2 - 3 } & $\mathrm{FZ}$ & $\mathbf{0 . 2 7}$ \\
\cline { 2 - 3 } & $\mathrm{AZ}$ & $\mathbf{0 . 4 9}$ \\
\hline
\end{tabular}

Table 2. Repeatability of the key variables.

\begin{tabular}{|l|c|c|c|c|c|}
\hline Variable & Zone & $r$ & SE & $95 \%$ CI & P [LRT] \\
\hline Velocity & BZ & 0.84 & 0.14 & $0.433-0.954$ & $3.75^{-07}$ \\
\hline \multirow{2}{*}{$\begin{array}{l}\text { Dis- } \\
\text { tance }\end{array}$} & FZ & 0.734 & 0.174 & $0.292-0.919$ & $3.13^{-05}$ \\
\cline { 2 - 6 } & $\mathrm{AZ}$ & 0.816 & 0.151 & $0.37-0.944$ & $1.32^{-06}$ \\
\cline { 2 - 6 } & $\mathrm{BZ}$ & 0.779 & 0.168 & $0.274-0.937$ & $6.94^{-06}$ \\
\hline \multirow{2}{*}{ Index $D$} & $\mathrm{BZ}$ & 0.763 & 0.174 & $0.257-0.93$ & $1.16^{-05}$ \\
\cline { 2 - 6 } & $\mathrm{AZ}$ & 0.615 & 0.203 & $0.088-0.87$ & 0.00069 \\
\hline
\end{tabular}

\section{Discussion}

Sociability of animals is studied in Crawley's three-chamber partner preference tests as the motivation to engage in social behavior or as preference to interact "with social over nonsocial object". The animal stimulus is confined in wire-mesh container, which constrains its mobility but permits audio, visual, and olfactory contacts, and a focal individual makes a choice between two equivalent chambers with a social $v s$. nonsocial object (Crawley, 2000, 2004; Moy et al., 2004; Millan \& Bales, 2013). In our test, we have kept on the principle idea of the classic preference test, but use designated zones instead of the distinct chambers.

The size of the arena was small enough for quick scanning and large enough to distinguish zones different in function. Sorex compared to the Crocidura shrews

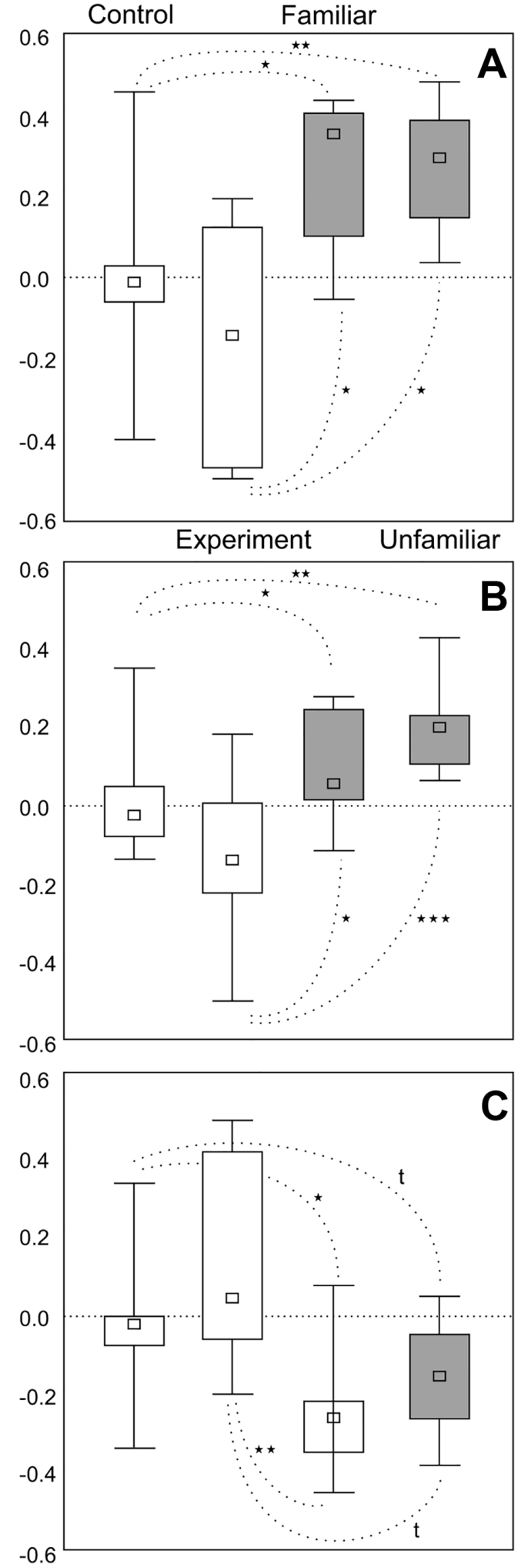

Fig. 3. Indexes of dominance of a variable the zone of stimulus animal - AZ: a - duration $\left(I_{t}\right), \mathrm{b}$ - distance $\left(I_{d}\right)$, and c velocity $\left(I_{v}\right)$. The dashed line indicates an index level similar to that expected when there are no differences. $* *-p<0.01$, $* * *-p<0.001 ; \mathrm{t}$ - tendency $(p<0.1)$; trials with animals living in pairs - gray boxes. Abbreviations see in Fig. 2. 
were found bolder, faster began exploration and systematically scanned the maze (Page et al., 2012; von Merten \& Siemers, 2012). In our test, common shrews started to explore the arena since the beginning of a trial without prolonged habituation phase. Five-minute trial was sufficient to obtain data for the analyses. The shrews scanned the entire area of arena, quickly discovered both containers, and carefully explored them. Taking into account that the track was obtained for the center of the image, the zone width was taken to be 0.5 body length, i.e., $3 \mathrm{~cm}$ from the edge of objects. The size of the containers and their position in the arena make it possible to exclude activity in the corners of arena from the activity associated with the container (see Fig. 1B). The density of tracks around the containers, $D$-index, was significantly greater than that near the border of arena. A significant increase in the sociability of the common shrew, followed socialization indicates that individuals have detected animal in a container (see Fig. 2). This reaction is in correspondence with our expectation based on contact tests (Kalinin \& Shchipanov, 2003). However, communal living is rather artificial situation for common shrews and we made these trials just to reveal whether there is any response on social stimulus at all in the species.

The distance traveled and time measurements are the most sensitive characteristics of activity in various open field experiments (Nagaraju et al., 2010; Tatem et al., 2014). The distance was found a good measure but not a complete measure of activity in a zone. Shrew movements were reduced with careful examination of an object. In such cases, the distance variable did not entirely reflect the attention to the studying subject. As a result, index of dominance in time was more prominent and informative than that in distance (see Fig. 3).

Velocity was studied as additional variable. Along with time and distances, the velocity characterizes anxiety of an animal (Kalueff et al., 2006; Lezak et al., 2017). The pace of movement in the test supposedly reflects excitement and anxiety, i.e., more agitated animals moved with greater velocity. Individually housed shrews consistently manifested greater velocity in the zone of stimulus animal compared with animals living in pairs. Significantly lower velocity in the latter case could indicate more thorough exploration of social object.

The test conditions and the variables permit to distinguish both situational and individual differences in sociability of the common shrews. Animal individuality significantly affected variables related to proactive behavior traits, which were found repeatable. Repeatability was not found in sociability. Also, high repeatability of activity and not of offensive behavior in the common shrew was found in contact tests (von Merten et al., 2017).

ACKNOWLEDGEMENTS. This work was supported by the Russian Foundation for Basic Research (grant No. 19-04-00985).

\section{References}

Buchanan K., Burt de Perera T., Carere C., Carter T., Hailey A., Hubrecht R., Jennings D., Metcalfe N., Pitcher T., Peron F., Sneddon L., Sherwin C., Talling J., Thomas R. \& Thompson M. 2012. Guidelines for the treatment of animals in behavioural research and teaching // Animal Behaviour. Vol.83. P.301-309.

Churchfield S. 1990. The Natural History of Shrews. London: Christopher Helm. 178 p.

Churchfield S. \& Searle J.B. 2008. Common shrew // Harris S. $\&$ Yalden D.W. (eds.) Mammals of the British Isles, Handbook. 4th edn. London: The Mammal Society. P.257-265.

Crawley J. 2000. What's Wrong with My Mouse? Behavioral Phenotyping of Transgenic and Knockout Mice. New York: John Wiley and Sons, Inc. 544 p.

Crawley J.N. 2004. Designing mouse behavioral tasks relevant to autistic-like behaviors // Mental retardation and developmental disabilities research reviews. Vol.10. P.248-258.

Croin Michielsen N. 1966. Intraspecific and interspecific competition in the shrews Sorex araneus L. and S. minutus L.// Archives Néerlandaises de Zoologie. Vol.17. P.73-74.

Crowcroft P. 1957. The Life of the Shrew. London: Max Reinhardt. $166 \mathrm{p}$.

Crowcroft W.P. 1955. Notes on the behaviour of shrews // Behaviour. Vol.8. P.63-80.

File S.E. \& Hyde J.R.G. 1978. Can social interaction be used to measure anxiety? // British Journal of Pharmacology. Vol.62. P.19-24

File S.E. \& Seth P. 2003. A review of 25 years of the social interaction test // European Journal of Pharmacology. Vol.463. P.35-53.

Kalinin A.A. \& Shchipanov N.A. 2003. [Density dependent behaviour in red-toothed shrews (Sorex araneus, S. caecutiens, and S. minutus) in wild and in experiment] // Izvestiya Akademii Nauk SSSR, Seria Biologicheskaia. Vol.6. P. 689-697 [in Russian, with English summary].

Kalinin A.A., Shchipanov N.A. \& Demidova T.B. 1998. [Behavior of four species of shrews Sorex isodon, S. araneus, $S$. caecutiens, and $S$. minutus (Insectivora, Soricidae) in interspecific contacts] // Zoologicheskii Zhurnal. Vol.77. P.838-849 [in Russian, with English summary].

Kalueff A.V., Keisala T., Minasyan A., Kuuslahti M. \& Tuohimaa P. 2006. Temporal stability of novelty exploration in mice exposed to different open field tests // Behavioural Processes. Vol.72. P.104-112.

Kouptsov A.V 2013. [Homing of yearlings of shrews (Sorex araneus and Sorex caecutiens, Insectivora, Soricidae)] // Zoologicheskii Zhurnal. Vol.92. P.941-954 [in Russian, with English summary].

Lezak K.R., Missig G. \& Carlezon W.A., Jr. 2017. Behavioral methods to study anxiety in rodents // Dialogues in Clinical Neuroscience. Vol.19. P.181-191.

von Merten S. \& Siemers B.M. 2012. Exploratory behaviour in shrews: fast-lived Sorex versus slow-lived Crocidura // Animal Behaviour. Vol.84. P.29-38.

von Merten S., Zwolak R. \& Rychlik L. 2017. Social personality: a more social shrew species exhibits stronger differences in personality types // Animal Behaviour. Vol.127. P.125-134. 
Millan M.J. \& Bales K.L. 2013. Towards improved animal models for evaluating social cognition and its disruption in schizophrenia: The CNTRICS initiative // Neuroscience and Biobehavioral Reviews. Vol.37. P.2166-2180.

Moraleva N.V. 1989. Intraspecific interactions in the common shrew Sorex araneus in Central Siberia // Annales Zoologici Fennici. Vol.26. P.423-432.

Moy S.S., Nadler J.J., Perez A., Barbaro R.P., Johns J.M., Magnuson T.R., Piven J. \& Crawley J.N. 2004. Sociability and preference for social novelty in five inbred strains: an approach to assess autistic-like behavior in mice // Genes, Brain, and Behavior. Vol.3. P.287-302.

Nakagawa S. \& Schielzeth H. 2010. Repeatability for Gaussian and non-Gaussian data: A practical guide for biologists // Biological Reviews. Vol.85. P.935-956.

Nagaraju K., Carlson G. \& De Luca A. 2010. Behavioral and locomotor measurements using open field animal activity monitoring system// TREAT-NMD.DMD_M.2.1.002.P.1-9.

Oleinichenko V.Y. 2007. [Behavior of the common (Sorex araneus), musked (Sorex caecutiens) and pygmy (Sorex minutes) shrews at developed and alien territory] // Zoologicheskii Zhurnal. Vol.86. P.1259-1271 [in Russian, with English summary].

Oleinichenko V.Y. 2012. Behavioral interactions of adult females of the common shrew (Sorex araneus) with conspecifics on familiar territory // Biology Bulletin. Vol.39. P.351-359.

Rychlik L. 1998. Evolution of social systems in shrews // Wójcik J.M. \& Wolsan M. (eds.). Evolution of Shrews. Białowieża: Mammal Research Institute Polish Academy of Sciences. P.347-406.

Rychlik L. \& Zwolak R. 2005. Behavioural mechanisms of conflict avoidance among shrews // Acta Theriologica. Vol.50. P.289-308.

Rychlik L. \& Zwolak R. 2006. Interspecific aggression and behavioural dominance among four sympatric species of shrews // Canadian Journal of Zoology. Vol.84. P.434-448.

Searle J.B. 1985. Methods for determining the sex of common shrews (Sorex araneus) // Journal of Zoology. Vol.206. P.279-282.
Shchipanov N.A., Kalinin A.A., Demidova T.B., Oleinichenko V.Yu., Aleksandrov D.Yu. \& Kouptzov A.V. 2005. Population ecology of red-toothed shrews, Sorex araneus, S. caecutiens, S. minutus, and S. isodon, in Central Russia // Merritt J.F., Churchfield S., Hutterer R. \& Sheftel B.I. (eds.). Advances in the Biology of Shrews II. Special Publication of the International Society of Shrew Biologists, New York. P.201-216.

Shchipanov N.A., Kalinin A.A., Oleinichenko V.Yu. \& Demidova T.B. 1998. [General behavioural characteristics of shrews Sorex araneus, S. caecutiens, S. minutus, and S. isodon (Insectivora, Soricidae)] // Zoologicheskii Zhurnal. Vol.2. P.300-312 [in Russian, with English summary].

Shchipanov N.A., Zima J. \& Churchfield S. 2019. Introducing the common shrew // Searle J., Polly P. \& Zima J. (eds.). Shrews, Chromosomes and Speciation (Cambridge Studies in Morphology and Molecules: New Paradigms in Evolutionary Bio). Cambridge: Cambridge University Press. P.19-67.

Shillito J.F. 1963a. Field observation on the growth, reproduction and activity of a woodland population of the common shrew Sorex araneus L. // Proceedings of the Zoological Society of London. Vol.140. P.99-113.

Shillito J.F. 1963b. Observations on the range and movements of a woodland population of the common shrew Sorex araneus L. // Proceedings of the Zoological Society of London. Vol.140. P.533-46.

Stoffel M.A., Nakagawa S. \& Schielzeth H. 2017. rptR: repeatability estimation and variance decomposition by generalized linear mixed-effects models // Methods in Ecology and Evolution. Vol.8. P.1639-1644.

Tatem K.S., Quinn J.L., Phadke A., Yu Q, Gordish-Dressman H. \& Nagaraju K. 2014. Behavioral and locomotor measurements using an open field activity monitoring system for skeletal muscle diseases // Journal of Visualized Experiments. Vol.91. P.1-7. 